\title{
The Influence of Sialylation on Glycan Negative Ion Dissociation and Energetics
}

\author{
Jennifer L. Seymour, Catherine E. Costello, and Joseph Zaia \\ Department of Biochemistry, Mass Spectrometry Resource, Boston University School of Medicine, Boston, \\ Massachusetts, USA
}

For the analysis of native glycans using tandem mass spectrometry (MS), it is desirable to choose conditions whereby abundances of cross-ring cleavages indicative of branch positions are maximized. Recently, negative ion tandem mass spectrometry has been shown to produce significantly higher abundances of such ions in glycans compared to the positive ion mode. Much of this prior work has concerned fragmentation patterns in asialo glycans. The present work compares the abundances of critical cross-ring cleavage ions using negative mode tandem mass spectrometry for milk oligosaccharides and $N$-linked glycans. For comparison, product ion formation was studied for deprotonated and nitrated ions formed from asialo glycans and deprotonated ions from sialylated glycans. Breakdown profiles demonstrate clearly that more energy was required to fragment sialylated compounds to the same extent as either their asialo or nitrate adducted counterparts. The extraction of a proton from a ring hydroxyl group during the ionization process may be viewed, qualitatively, as imparting significantly more energy to the ion than would that from a molecule bearing an acidic group, so that acidic glycans are more stable in the gas phase, as the negative charge resides on the carboxyl group. These results have strong practical implications because a major portion of glycans released from mammalian proteins will be sialylated. (J Am Soc Mass Spectrom 2006, 17, 844-854) (C) 2006 American Society for Mass Spectrometry

$\mathrm{T}$ The most information-rich tandem mass spectra of oligosaccharides are those in which a combination of abundant glycosidic bond and cross-ring cleavages is observed. Cross-ring cleavages at branching residues and those where linkages are known to vary in the given oligosaccharide or glycoconjugate class provide particularly valuable information. Although abundant A-type and X-type cross-ring cleavages are observed using high-energy collisionalinduced dissociation (CID) [1,2], most modern mass analyzers operate in the low-energy regime. Thus, positive ion CID MS using triple quadrupole, ion trap, quadrupole orthogonal time-of-flight, and FT-ICR analyzers results in low-energy fragmentation in which Band Y-type ions and only those cross-ring cleavage ions that result from particularly facile processes are abundant [3]. Recently, high-energy CID fragmentation, including X-type cross-ring cleavage ions, has been observed for a variety of nonacidic oligosaccharides using matrix-assisted laser desorption/ionization (MALDI) tandem time-of-flight analyzers [4,5]. However, since fragile oligosaccharides, particularly polysialylated [6], and polysulfated molecules $[7,8]$ have been observed to undergo prompt fragmentation in the vacuum MALDI source and metastable decomposition in the analyzer,

Published online April 17, 2006

Address reprint requests to Dr. J. Zaia, Department of Biochemistry, Mass Spectrometry Resource, Boston University School of Medicine, 670 Albany St., Rm. 509, Boston, MA 02118, USA. E-mail: jzaia@bu.edu they are more amenable to electrospray ionization. Negatively charged neutral oligosaccharides undergo fragmentation at very low collision energies [9-11], and such ions are also more amenable to electrospray ionization than MALDI. Now, there remains no commercial instrument option for producing high-energy CID for fragile molecules. Introduction of an orthogonal vibrationally cooled MALDI source or an electrospray source for the tandem time-of-flight mass analyzer has the potential to solve this problem.

Among the early applications of the fast atom bombardment (FAB) ionization technique was the analysis of neutral and acidic glycoconjugates and oligosaccharides as negative ions [12]; glycosidic bond cleavages were observed in the MS mode for a number of compound classes [13-17]. Comparison of lactosylcerebroside tandem mass spectra showed that ${ }^{0,2} \mathrm{~A}_{2}$ and ${ }^{2,4} \mathrm{~A}_{2}$ cross-ring cleavage ions were observed in negative but not in the positive ionization mode [18], illustrating that the negative mode provides unique and useful information for structural analysis.

Significant differences were also observed, depending on the presence of Neu5Ac in glycoconjugates. For example, high-energy tandem MS of ganglioside asialo $\mathrm{GM}_{1}$ (Gal $\beta 1-3 \mathrm{GalNAc} \beta 1-4 \mathrm{Gal} \beta 1-4 \mathrm{Glc}-\mathrm{O}-\mathrm{ceramide})$ produced an abundant series of A-type cross-ring cleavages at the 2-, $3-$, and 4-residues that were not observed in the tandem mass spectrum of the sialylated variant [18]. Asialo $\mathrm{GM}_{1}$ was also observed to produce an abundant ion at $\mathrm{m} / \mathrm{z}$ 202.07 from $C_{2} / Z_{3}$ fragmentation that was absent in 
spectra of variants containing a 4-linked GalNAc [1, 18]. Such product ions were observed in the negative mode for other asialo glyconjugates [19].

Native neutral oligosaccharide anions tend to produce abundant C-type ions during negative CID, and A-type cross ring cleavages are observed across residues that are (1-4) or (1-6) linked [20-22]. A-type ions are useful for determining the presence of a core Fuc residue in $N$-linked glycans [23] and have been used as diagnostic tools for detecting free oligosaccharides in the presence of glycopeptides [24]. The (1-3)-linked residues, or those with a blocked hydroxyl group in the 3-position, produce a C-type cleavage at the reducing side and a Z-type cleavage at the nonreducing side, a combination that is now termed D-type [10]. It is common to release $O$-linked glycans as reducing end alditols, and it has been demonstrated that abundant Z-type fragment ions are formed from dissociation of negatively charged precursor ions generated from asialo structures [25].

CID precursor ion studies of disaccharides indicated that the ${ }^{2,4} \mathrm{~A}_{2}$ ion for (1-4) or (1-6) linked structures was produced both directly from the $[\mathrm{M}-\mathrm{H}]^{-}$precursor ion and from the ${ }^{0,2} \mathrm{~A}_{2}$ ion [20]. The mechanism of ${ }^{0,2} \mathrm{~A}$-type ion formation has been generally accepted to involve an anomeric ring opening followed by retroaldol rearrangement involving the hydroxyl group in the 3-position [26-29]. This retro-aldol mechanism explains the absence of ${ }^{0,2} \mathrm{~A}$-type cross-ring cleavages across 3-linked residues, since a free $\mathrm{OH}$ group in this position is required for the rearrangement. The analogous formation of X-type cross-ring cleavages from Y-type ions in low-energy CID tandem mass spectra are not generally observed because anomeric ring opening cannot occur. Thus, there is no facile rearrangement mechanism for two-bond cleavage to form X-type ions. Such X-type ions can only be formed from higher energy processes that do not involve prior cleavage of a glycosidic bond. Exceptions are cases, such as glycans containing a nonreducing terminal 4,5-unsaturated uronic acid residue, where the ion structure gives rise to a rearrangement mechanism, such as the retro-Diels Alder [27, 29], that occurs at low-energy. Other exceptions arise for small structures in which few other fragmentation pathways exist to compete with X-type cross-ring cleavage (see, for example, Figure 5).

Low-energy CID tandem MS of negative ions has proven to be useful for differentiating type 1 (-Gal $\beta 1$ 3GlcNAc-) and type 2 (-Gal $\beta 1-4$ GlcNAc-) chains and patterns of fucosylation in native milk oligosaccharides $[10,30,31]$ and closed-ring glycosylamine labeled neutral oligosaccharides [32]. A D-type ion results from cleavage of the 1- and 3-substituents of the core Man residue. As such, its $m / \mathrm{z}$ value determines the mass of the 6-branch [23, 32-35]. Deprotonated, neutral, Nlinked oligosaccharides have been observed to produce in-source fragmentation during ESI in some cases [11]. Nitrate adducts were observed to produce more abundant precursor ions, to resist in-source fragmentation, and to produce patterns of C-, A-, and D-type product ions similar to those of deprotonated ions. Such adducts have been shown to produce useful fragmentation for high mannose [36] and asialo complex N-linked glycans [37].

Much about dissociation of glycans in the negative mode remains to be explored. In particular, there is need for direct comparison of the energetics of glycan fragmentation for neutral-deprotonted, neutral-anion adducted, and acidic-deprotonated ions. To meet this need, breakdown profiles were generated for a series of isomeric milk oligosaccharides, Lewis antigens, and $\mathrm{N}$-linked glycans. These data demonstrate that the presence of Neu5Ac strongly influences both the energetics and product ion pattern for native glycans. The formation of glycan product ions requires significantly higher collision energies relative to those of neutraldeprotonated precursors and relative abundances of key A- and D-type ions are diminished. For anion adducts, the dissociation of nitrate competes with formation of ions from glycan cleavage. These trends are explained in terms of the energetics of the ionization process. These results show that tandem mass spectrometric analysis schemes should be setup to fragment neutral deprotonated ions with relatively low energies and sialylated ions with relatively high energies.

\section{Experimental}

Gal $\beta 3$ (Fuc $\alpha 4$ )GlcNAc (Lewis a, Le ${ }^{\mathrm{a}}$ ), Gal $\beta 4$ (Fuc $\alpha 3$ ) GlcNAc (Lewis $x$, Le $^{\mathrm{x}}$ ), Neu5Ac $\alpha 3$ Gal $\beta 3$ (Fuc $\alpha 4$ )GlcNAc (sialyl Lewis a, sLea), and Neu5Ac $\alpha 3$ Gal $\beta 4$ (Fuc $\alpha 3$ ) GlcNAc (sialyl Lewis $x, s L e^{x}$ ) were purchased from VLabs, (Covington, LA). Gal $\beta 3$ GlcNAc $\beta 3$ Gal $\beta 4$ Glc (Lacto$N$-tetraose, LNT), Gal $\beta 4$ GlcNAc $\beta 3 \mathrm{Gal} \beta 4 \mathrm{Glc}$ (lacto- $N$ neotetraose, LNnT), Neu5Ac $\alpha 3 \mathrm{Gal} \beta 3 \mathrm{GlcNAc} \beta 3 \mathrm{Gal} \beta 4 \mathrm{Glc}$ (LS tetrasaccharide a, LST-a), Neu5Ac $\alpha 6$ Gal $\beta 4$ GlcNAc $\beta 3$ Gal $\beta 4$ Glc (LS tetrasaccharide c, LST-c), Neu5Ac $\alpha 3-$ Gal $\beta 4 \mathrm{GlcNAc} \beta 3 \mathrm{Gal} \beta 4 \mathrm{Glc}$ (LS tetrasaccharide d, LST-d), biantennary asialo- $N$-linked glycan Gal $\beta 4$ GlcNAc $\beta 2-$ Man $\alpha 6$ (Gal $\beta 4$ GlcNAc $\beta 2$ Man $\alpha 3$ )Man $\beta 4$ GlcNAc $\beta 4$ GlcNAc (N2), and biantennary disialyl- $N$-linked glycan Neu5Ac $\alpha 3 / 6$ Gal $\beta 4$ GlcNAc $\beta 2$ Man $\alpha 6$ (Neu5Ac $\alpha 3 / 6 \mathrm{Gal} \beta 4$ GlcNAc $\beta 2 M a n \alpha 3$ )Man $\beta 4$ GlcNAc $\beta 4 G l c N A c$ (NA2) were purchased from Calbiochem, (Darmstadt, Germany). Lacto- $N$-difucohexaose I (LNDFH I) was purchased from Prozyme (San Leandro, CA) Structures for these glycans are given in the figures. All compounds were used without further purification. Samples were prepared in a solution made from 30\% HPLC grade methanol, 70\% HPLC grade water, and $0.1 \%$ ammonium hydroxide (J. T. Baker, Philipsbury, NJ). The final concentration of the oligosaccharide analyte ranged from $200 \mathrm{fmol} / \mu \mathrm{L}$ to 10 $\mathrm{pmol} / \mu \mathrm{L}$. Nitrated samples were prepared in a $30 \%$ methanol $70 \%$ water solution that was brought to $0.1 \mathrm{M}$ $\mathrm{NO}_{3}{ }^{-}$with $\mathrm{NH}_{4} \mathrm{NO}_{3}$, (Aldrich, Milwaukee, WI). Methyl esterification was performed by reacting the dried oligosaccharide with $0.5 \mathrm{M}$ methanolic $\mathrm{HCl}$ for $30 \mathrm{~min}$ at $37^{\circ} \mathrm{C}$. All samples were analyzed using negative ion nanospray 
on an MDS Sciex/API Qstar QoTOF MS. Instrumental parameters were declustering potential $-20 \mathrm{~V}$, focusing potential $-168 \mathrm{~V}$, declustering potential II $-20 \mathrm{~V}$, CAD gas of argon 3, IRD $6.0 \mathrm{~V}$, IRW $5.0 \mathrm{~V}$, curtain gas $10 \mathrm{~L} / \mathrm{s}$, spray voltage $-1150 \mathrm{~V}$. Tandem mass spectra of either singly or doubly charged precursor ions were acquired at varying collision energies, as shown in the figure axes. Mass spectra were collected for one minute per time point and were averaged for analysis. Breakdown curves for ions of interest were plotted as the percentage of the total ion intensity versus the collision energy. Applied Biosystems Analyst software was used for all spectral analysis and the threshold for peak selection was held to $1 \%$ of the intensity of the base peak.

\section{Results}

\section{Milk Oligosaccharides}

Figure 1a and $\mathrm{b}$ describe diagrammatically the tandem mass spectra of LNT and LNnT, respectively, at $-10 \mathrm{~V}$ collision energy, while Figure 1c and d describe those of the sialylated variants LST-a and LST-d, respectively, at $-37.5 \mathrm{~V}$ collision energy. Both LNT and LNnT produced abundant C-type ions, as expected for deprotonated neutral glycans $[10,30]$. LNT contains a $(\beta 1,3)-$ linked GlcNAc residue and its deprotonated ion dissociates to form a $\mathrm{D}_{1-2}$ ion at $m / z$ 202.07. LNnT, by contrast, contains a $(\beta 1,4)$-linked GlcNAc residue and dissociates to form a ${ }^{0,2} \mathrm{~A}_{2}$ ion at $\mathrm{m} / \mathrm{z} 281.08$. Sialylated variants LST-a (1c) and LST-d (1d) produce distinctly different patterns with abundant $B_{1}$ ions formed from the Neu5Ac residue and other ions in comparatively low abundances. A clear series of C-type ions is lacking from the tandem mass spectra of the sialylated variants, an observation consistent with the conclusion that the fragmentation pathways differ significantly between the acidic and the neutral structures. LST-a, the $(\alpha 2,3)$ sialylated analog of LNT, forms a D-type ion at $\mathrm{m} / \mathrm{z}$ 202.07. Several ions deriving from ${ }^{0,2} \mathrm{~A}$-type cleavage to the GlcNAc residue are observed in the tandem mass spectrum of LST-d, the analog of LNnT. LST-c differs

Figure 1. (a)-(e) Diagrammatic representation of tandem mass spectra of milk oligosaccharides. The product ion abundances relative to the precursor ion are as follows: ion, $\mathrm{m} / \mathrm{z}$, relative abundance (a) LNT collision energy (CE) -10 V: $\mathrm{D}_{1-2}, 202.07,13$; $\mathrm{C}_{2}, 382.14,27 ; \mathrm{C}_{3}, 544.18,33 ;{ }^{0,2} \mathrm{~A}_{4}, 646.23,6 ;[\mathrm{M}-\mathrm{H}]^{-}, 706.27,100$; (b) LNnT CE -10 V: ${ }^{0,2} \mathrm{~A}_{2}, 281.08$ 14; $\mathrm{C}_{2}, 382.14,43 ; \mathrm{C}_{3}, 544.20,33$; ${ }_{0,2} \mathrm{~A}_{4}, 646.20,5$; $[\mathrm{M}-\mathrm{H}]^{-}, 706.24,100$; (c) LST-a CE - 37.5 V: $\mathrm{D}_{2-3}$, 202.08, 27; $\mathrm{B}_{1}, 290.09,104 ; \mathrm{C}_{3} / \mathrm{Y}_{4}, 382.13,5 ;{ }^{2,4} \mathrm{~A}_{5} / \mathrm{Y}_{4}, 586.20,5$; [M $-\mathrm{H}^{-}$, 997.31, 100; (d) LST-d CE -37.5 V: $\mathrm{Z}_{1}, 161.06,14 ; \mathrm{Y}_{1}, 179.07$, 34; ${ }^{0,2} \mathrm{~A}_{3}-\mathrm{H}_{2} \mathrm{O} / \mathrm{Y}_{4}, 263.09,27 ;{ }^{0,2} \mathrm{~A}_{3} / \mathrm{Y}_{4}, 281.11,11 ; \mathrm{B}_{1}, 290.10,118$; $\mathrm{C}_{3} / \mathrm{Y}_{4}, 382.15,7 ;{ }^{0,2} \mathrm{~A}_{3}-2\left(\mathrm{H}_{2} \mathrm{O}\right), 536.17,22 ;{ }^{0,2} \mathrm{~A}_{3}-\mathrm{H}_{2} \mathrm{O}, 554.19,7$; ${ }_{0,2} \mathrm{~A}_{5}$, 937.31, 4; $[\mathrm{M}-\mathrm{H}]^{-}$, 997.35, 100; (e) LST-c CE - 47.5 V: $\mathrm{Y}_{1}$, 179.08, 9; ${ }^{0,2} \mathrm{~A}_{3}-\mathrm{H}_{2} \mathrm{O} / \mathrm{Y}_{4}, 263.09,4 ; \mathrm{B}_{1}, 290.11,55 ; \mathrm{Z}_{2}-\mathrm{H}_{2} \mathrm{O}, 306.13,6$; ${ }^{0,2} \mathrm{~A}_{3}, 572.20,6 ;{ }^{2,}{ }^{4} \mathrm{~A}_{5} / \mathrm{Y}_{4}, 586.19,4 ; \mathrm{C}_{3}, 673.23,8 ; \mathrm{C}_{4}, 835.23,11$; ${ }^{0,2} \mathrm{~A}_{5}, 937.28,20$; $[\mathrm{M}-\mathrm{H}]^{-}, 997.28,100$; (f) monosaccharide symbols used; (g) plot of precursor ion abundances versus collision energy for milk oligosaccharides. from LST-d in having a $(\alpha 2,6)$ sialic acid linkage. The corresponding tandem mass spectrum (Figure 1e) shows decreased product ion abundances owing to the apparent increased stability of the precursor ion relative to the LST-a and LST-d.

The ion intensity of the $[\mathrm{M}-\mathrm{H}]^{-}$precursor ions, $m / z$

a. LNT

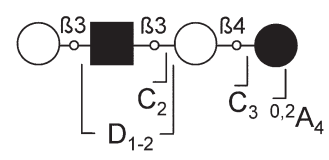

b. LNnT
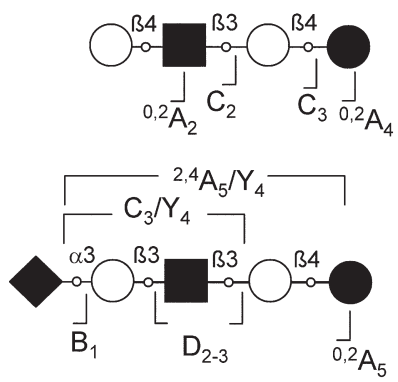

c. LST-a

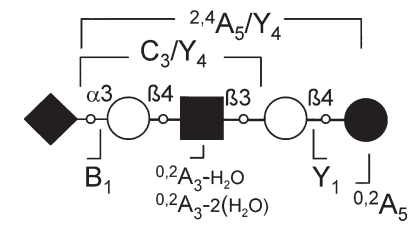

e. LST-C

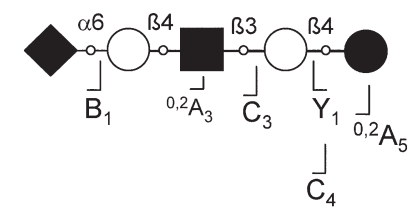

f.

d. LST-d

g.

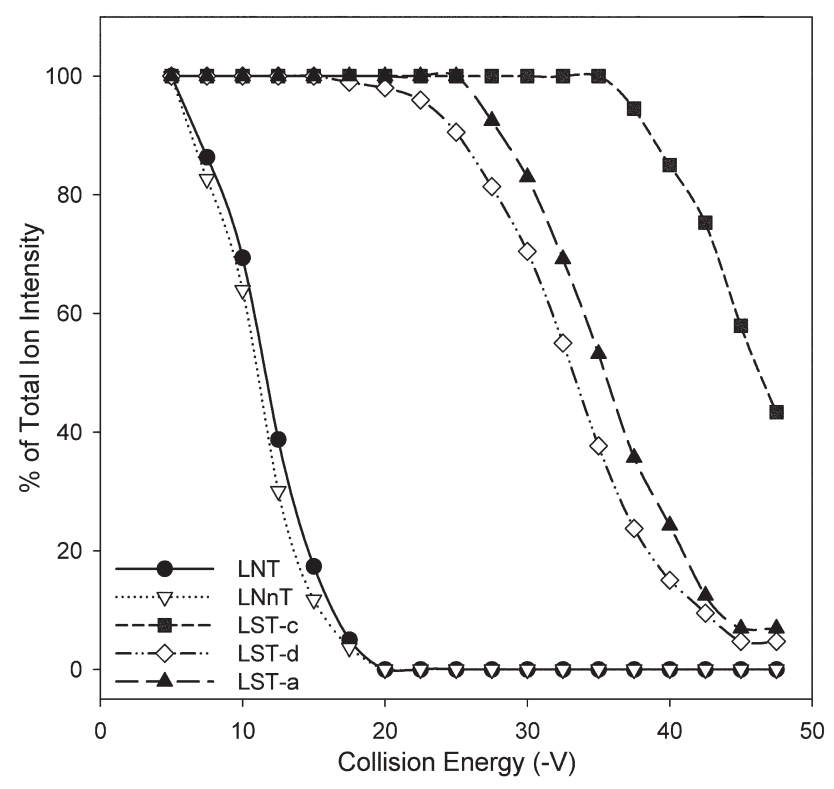


(a)

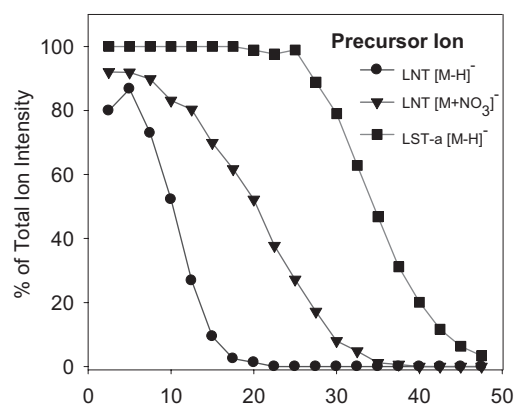

(b)

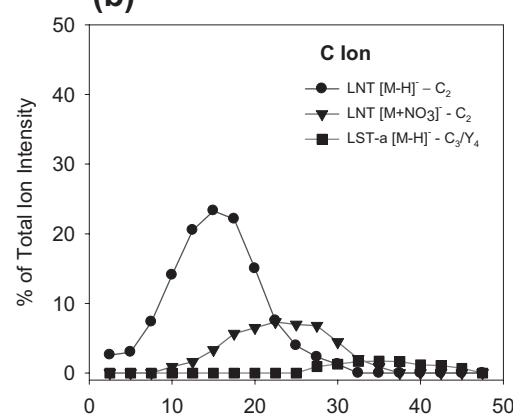

(c)

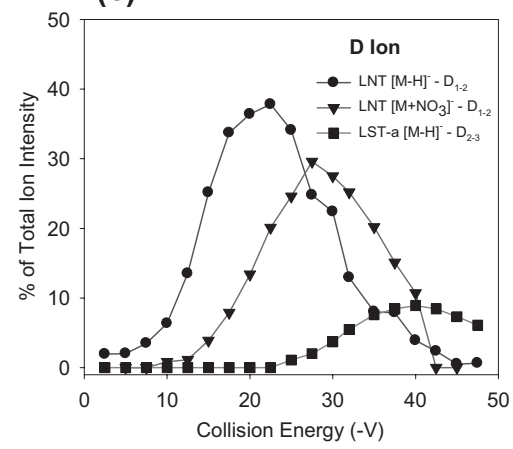

(d)

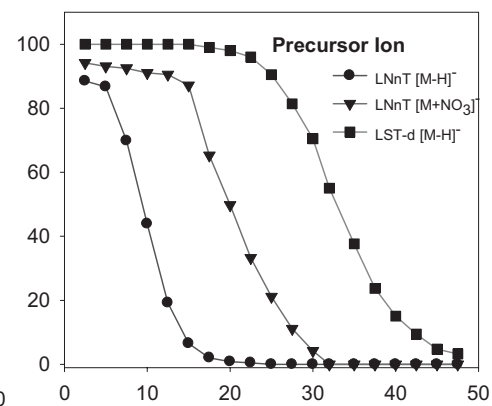

(e)

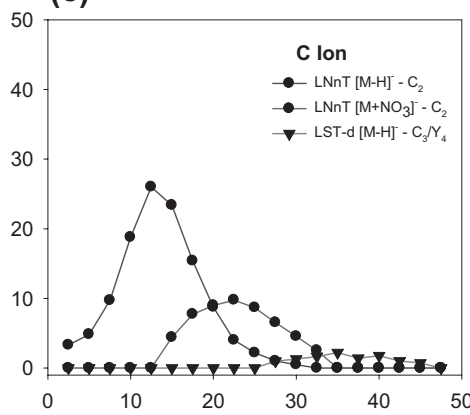

(f)

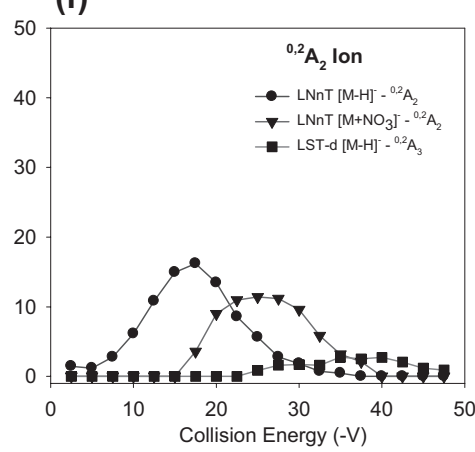

Figure 2. Abundances of precursor and product ions generated from LNT $[\mathrm{M}-\mathrm{H}]^{-}, \mathrm{LNT}[\mathrm{M}+$ $\left.\mathrm{NO}_{3}\right]^{-}$, LST-a $[\mathrm{M}-\mathrm{H}]^{-}$, LNnT $[\mathrm{M}-\mathrm{H}]^{-}, \mathrm{LNnT}\left[\mathrm{M}+\mathrm{NO}_{3}\right]^{-}$, and LST-d $[\mathrm{M}-\mathrm{H}]^{-}$as a function of collision energy. (a) Precursor ions LNT series, (b) C-type ions LNT series (c) D-type ions LNT series, (d) precursor ions LNnT series, (e) C-type ions LNnT series, and (f) A-type cross-ring cleavages LNnT series. Tandem mass spectra were acquired within a mass range of 100-2000 u.

706.27 in $1 \mathrm{a}$ and $1 \mathrm{~b}$ and $\mathrm{m} / \mathrm{z} 997.31$ in $1 \mathrm{c}$ and $1 \mathrm{~d}$, were monitored over a range of collision energies, as were the product ion intensities. The percent intensity of the precursor ions versus the collision energies for LNT, LNnT, their $(\alpha 2,3)$-sialylated analogs (LST-a, LST-d, respectively), and the $(\alpha 2,6)$-sialylated analog of LNnT (LST-c) are shown in Figure $1 \mathrm{~g}$. The $[\mathrm{M}-\mathrm{H}]^{-}$ions for the asialo oligosaccharides, LNT and LNnT, are reduced to $50 \%$ of their original intensity at $-10 \mathrm{~V}$ collision energy. By comparison, the sialylated variants LST-a, LST-d require -35 to $-40 \mathrm{~V}$ to reach $50 \%$ of their original intensity. LST-c, differing from LST-d in the $(\alpha 2,6)$ Neu5Ac linkage, requires even a greater amount of energy to fragment to the same extent, approximately $-45 \mathrm{~V}$.

Figure 1 illustrates that sialylated compounds require significantly more energy to fragment than their corresponding asialo-oligosaccharides, consistent with the conclusion that the formation of an $[\mathrm{M}-\mathrm{H}]^{-}$ion for neutral oligosaccharides imparts a significant amount of energy during the ionization process. The $[\mathrm{M}-\mathrm{H}]^{-}$ ions produced from the $(\alpha 2,3)$-linked sialylated forms of LNT (LST-a) and LNnT (LST-d), respectively, are produced by deprotonation of the carboxylic acid group and are lower in energy than precursor ions of asialooligosaccharides. Because the only structural difference between LST-d and LST-c is the sialic acid linkage, the data illustrate that the $(\alpha 2-6)$ bond is more stable than the $(\alpha 2-3)$ linkage. This result extends recent observations on differences in glycan negative product ion mass spectra depending on the sialic acid linkage [38-41].

Figure 2 compares the abundances of precursor ions derived from LNT, containing a $\beta(1,3)$-linked GlcNAc, and LNnT, containing $\beta(1,4)$-linked GlcNAc. Three forms of each ion are shown, $[\mathrm{M}-\mathrm{H}]^{-},\left[\mathrm{M}+\mathrm{NO}_{3}\right]^{-}$, 
and sialylated $[\mathrm{M}-\mathrm{H}]^{-}$. For LNT and LNnT, the $[\mathrm{M}-$ $\mathrm{H}]^{-}$ion decays at significantly lower energy than does the $\left[\mathrm{M}+\mathrm{NO}_{3}\right]^{-}$ion. Evidently, the formation of the $[\mathrm{M}$ $\left.+\mathrm{NO}_{3}\right]^{-}$ion imparts less energy, and the ions rearrange to form $[\mathrm{M}-\mathrm{H}]^{-}$ions, a process that requires higher CID energies [11]. The $[\mathrm{M}-\mathrm{H}]^{-}$ions from the sialylated forms, LST-a and LST-d, respectively, are more energetically stable than the $\left[\mathrm{M}+\mathrm{NO}_{3}\right]^{-}$ions of the neutral forms, as they require at least $14 \mathrm{~V}$ more collision energy than the nitrated adducts.

Tandem mass spectra were acquired using a range of 100-2000 $\mathrm{u}$, and thus do not show the formation of a nitrate ion at $\mathrm{m} / \mathrm{z} 62.0$ for nitrated precursors; as such they are useful for comparing the energetics of product ion formation. The formation of the nitrate ion is addressed in a later section. It is informative to monitor the C-type product ions formed from cleavage to the reducing side of the GlcNAc residue. These ions may be seen as precursors to the A- and D-type ions that are useful for differentiating Gal-GlcNAc linkage. C-type glycosidic bond cleavage ions are significantly more abundant for the $[\mathrm{M}-\mathrm{H}]^{-}$ions generated from LNT (Figure 2b) and LNnT (Figure 2e) than for the corresponding $\left[\mathrm{M}+\mathrm{NO}_{3}\right]^{-}$ions or the $[\mathrm{M}-\mathrm{H}]^{-}$ions from the sialylated variants. The abundance of the D-type ion, (Figure 2c) produced by C-type and Z-type fragmentation around the GlcNAc residue diminishes in the order LNT $[\mathrm{M}-\mathrm{H}]^{-}>$LNT $\left[\mathrm{M}+\mathrm{NO}_{3}\right]^{-}>$LST-a $[\mathrm{M}$ $-\mathrm{H}]^{-}$. This ion is absent for the LNnT-derived ions, as expected. Ions produced by cross-ring cleavages to the GlcNAc residue $\left({ }^{0,2} \mathrm{~A}_{2}\right.$ and $\left.{ }^{0,2} \mathrm{~A}_{2}-\mathrm{H}_{2} \mathrm{O}\right)$ are abundant for LNnT-derived ions (Figure 2f) but are absent in those from LNT. The amount of energy required to form A-type ions from cross-ring cleavage to the GlcNAc residue follows the order LNnT $[\mathrm{M}-\mathrm{H}]^{-}<\mathrm{LNnT}[\mathrm{M}$ $\left.+\mathrm{NO}_{3}\right]^{-}<$LST-d $[\mathrm{M}-\mathrm{H}]^{-}$.

\section{N-Linked Glycans}

Negative ion fragmentation of N-linked glycans results in formation of abundant ${ }^{0,2} \mathrm{~A}$ - and ${ }^{2,4} \mathrm{~A}$-type cross-ring cleavages to core GlcNAc residues [9], as is typical for glycans with a 4-linked reducing terminus [27]. D-type cleavages to the branching mannose residue are particularly useful for determining the mass of the 6-antenna [37, 42]. In addition, the linkage of HexNAc residues in the antennae may be discerned by the presence of ${ }^{0,2} \mathrm{~A}$-type cross-ring cleavages to 4 -linked residues, and D-type cleavage to 3 -linked residues [10, 30, 33]. Such patterns differentiate type 1 [Gal $\beta 1-3 \mathrm{GlcNAc}$ ] and type 2 [Gal $\beta 1-4 \mathrm{GlcNAc}$ ] chains. The ${ }^{2,4} \mathrm{~A}_{3}$ ion $(\mathrm{m} / \mathrm{z}$ 424.15) and ${ }^{0,2} \mathrm{~A}_{3}-\mathrm{H}_{2} \mathrm{O}(\mathrm{m} / \mathrm{z} 466.16$, ion $\mathrm{E}$ as previously described) are useful as indicators of the presence of Hex-HexNAc repeats in the antennae [37].

Figure 3 shows the tandem mass spectra of N2, a lactosamine-containing asialo biantennary $\mathrm{N}$-linked glycan, $[\mathrm{M}-2 \mathrm{H}]^{2-}$, the disialylated variant NA2, [M $2 \mathrm{H}]^{2}$ (Figure 3b) and methyl esterified NA2 $[\mathrm{M}-2 \mathrm{H}]^{2-}$ (Figure 3c). Although A-type cleavage to the core Glc-
NAc residues are highest in abundances, N2 [M $2 \mathrm{H}]^{2-}$ (Figure 3a) dissociates to form a $\mathrm{D}_{3,4}$ ion that determines the mass of the 6-branch and, by subtraction, the 3-branch. $\mathrm{A}^{0,2} \mathrm{~A}_{2}$ ion (termed ${ }^{0,2} \mathrm{~A}_{\mathrm{A}}, m / z 281$ ), indicative of a 4-linked antenna GlcNAc residue, is observed at higher collision energies (see Figure 4c). The sialylated NA2 $[\mathrm{M}-2 \mathrm{H}]^{2-}$ ion (Figure 3b) dissociates to form an abundant $\mathrm{B}_{1}$ ion with reduced abundances of all other product ions. Significantly higher collision energy is required for the observation of any product ions for the sialylated, relative to the asialo, precursor ion. In addition, D-type cleavage to the coreMan and A-type cleavage to the antenna GlcNAc residues are not observed for NA2, even at elevated collision energies. Methyl esterified NA2 $[\mathrm{M}-2 \mathrm{H}]^{2-}$ dissociates to form a pattern similar to that observed for $\mathrm{N} 2[\mathrm{M}-2 \mathrm{H}]^{2-}$ (Figure 3c) in that the useful D- and A-type cleavages are observed, in contrast to the pattern observed for underivatized NA2 $[\mathrm{M}-2 \mathrm{H}]^{2-}$. These ions are $\mathbf{D}_{4,5}(\mathrm{~m} / z$ 993.24, observed at higher collision energies, see Figure $4 d),{ }^{0,2} A_{3}(m / z 586.20)$ and ${ }^{2,4} A_{3}(m / z$ 526.20). An ion corresponding to the loss of methyl esterified Neu5Ac is notably absent. Therefore, the fragmentation pathways for methyl esterified NA2 are most like those of N2 $[\mathrm{M}-2 \mathrm{H}]^{2-}$. Methyl esterified NA2 $[\mathrm{M}-2 \mathrm{H}]^{2-}$ dissociates to produce losses of methanol from the precursor A-type cross ring cleavage ions to the core HexNAc residues.

The energetics of precursor ion breakdown and product ion formation are compared for the different ion forms in Figure 4. The tandem mass spectra were acquired using a range of $100-2000 \mathrm{u}$ so as to compare the energetics of formation of ions from dissociation of glycan bonds; the formation of nitrate ions at $\mathrm{m} / \mathrm{z} 62.00$ is addressed later in Figure 6. The plots show data from $\mathrm{N} 2[\mathrm{M}-2 \mathrm{H}]^{2-},\left[\mathrm{M}+2\left(\mathrm{NO}_{3}\right)\right]^{2-}, \mathrm{NA} 2[\mathrm{M}-2 \mathrm{H}]^{2-}$, and methyl esterified NA2 $[\mathrm{M}-2 \mathrm{H}]^{2-}$. The energy required to produce a $50 \%$ decrease in precursor ion abundance (Figure 4a) follows the order NA2 $[\mathrm{M}-2 \mathrm{H}]^{2-} \gg \mathrm{N} 2[\mathrm{M}$ $\left.+2\left(\mathrm{NO}_{3}\right)\right]^{2-} \gg \mathrm{N} 2[\mathrm{M}-2 \mathrm{H}]^{2-}$, methyl esterified NA2 $[\mathrm{M}-2 \mathrm{H}]^{2-}$. Because the formation of the N2 [M $2 \mathrm{H}]^{2-}$ ion imparts significant energy through abstraction of two ring hydroxyl protons, this ion undergoes fragmentation with little addition of collision energy. The $\left[\mathrm{M}+2\left(\mathrm{NO}_{3}\right)\right]^{2-}$ ion first undergoes loss of $\mathrm{NO}_{3}$ to form $\left[\mathrm{M}+\mathrm{NO}_{3}\right]^{-}$at $\mathrm{m} / \mathrm{z} 1702.21$ and then fragments to form singly charged product ions. The breakdown curve shown in Figure $4 \mathrm{a}$ is, thus, a sum of the abundances of the $\left[\mathrm{M}+2\left(\mathrm{NO}_{3}\right)\right]^{2-}$ and $\left[\mathrm{M}+\mathrm{NO}_{3}\right]^{-}$precursor ions. Disialylated N2 (NA2) as a $[\mathrm{M}-2 \mathrm{H}]^{2-}$ ion requires dramatically more collision energy to undergo cleavage of bonds in the glycan structure. This observation is consistent with the conclusion that the energy of the $[\mathrm{M}-2 \mathrm{H}]^{2-}$ ion, formed by the deprotonation of two carboxylic acid groups, is significantly lower than that formed from the asialo $\mathrm{N} 2$ by deprotonation of two ring hydroxyl groups. Because of this stability, significantly more energy must be added to the ion during the CID process to cleave glycan bonds. Methyl esterified 
(a)
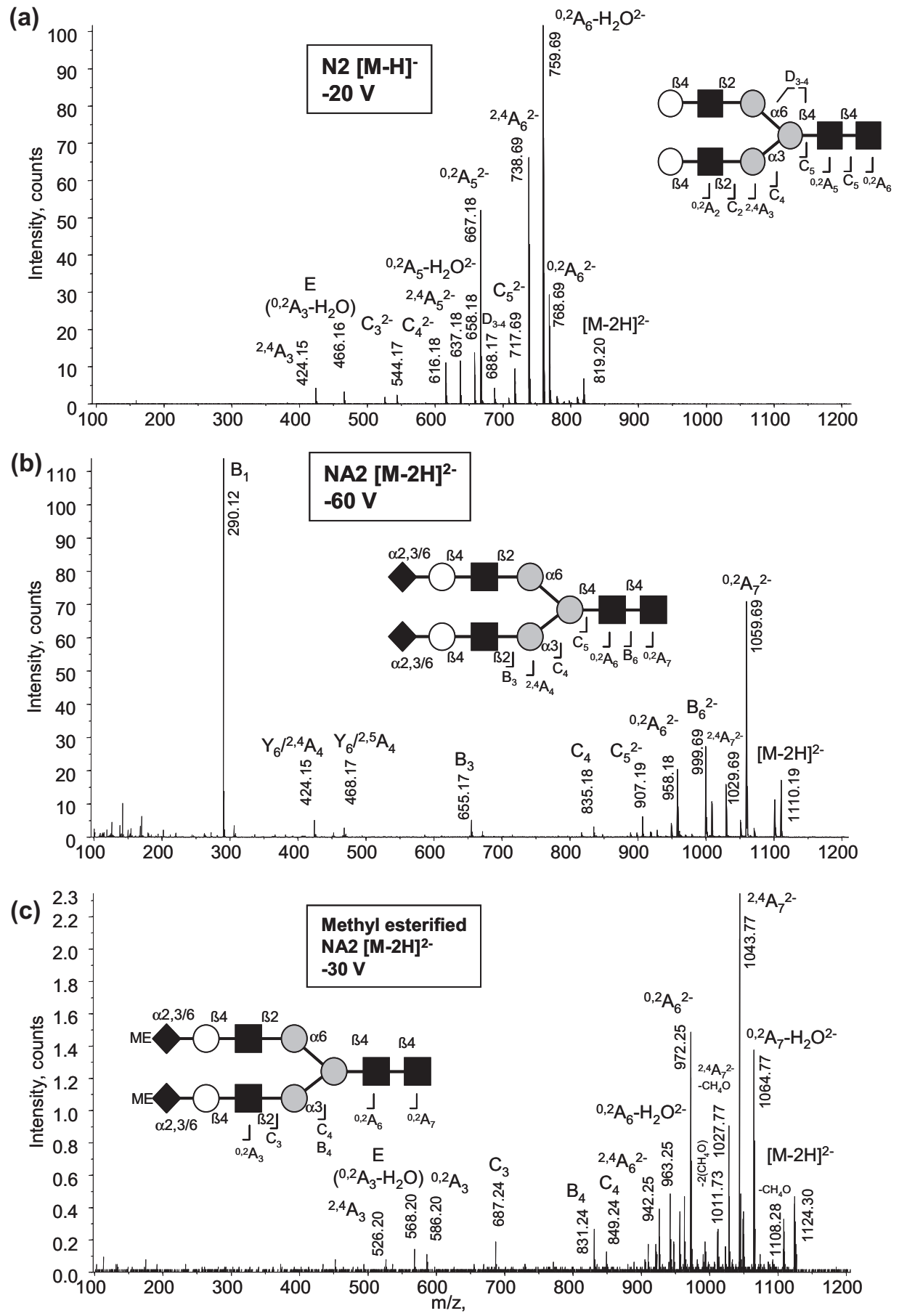

Figure 3. Tandem mass spectra of asialo- and sialylated biantennary $N$-linked glycans (a) N2 at CE $-20 \mathrm{~V},(\mathbf{b}) \mathrm{NA} 2$ at CE $-60 \mathrm{~V},(\mathbf{c})$ methyl esterified NA2 at CE $-30 \mathrm{~V}$. Symbols are defined in Figure $1, \mathrm{ME}=$ methyl ester.

NA2 $[\mathrm{M}-2 \mathrm{H}]^{2-}$ dissociates at similar energies as does $\mathrm{N} 2[\mathrm{M}-2 \mathrm{H}]^{2-}$, consistent with its formation through deprotonation of ring hydroxyl groups.

Cross-ring cleavages to the reducing end GlcNAc residue (termed $A_{R}$, Figure $4 b$ ) are observed at maximum abundances at $-30 \mathrm{~V}$ collision energy for $\mathrm{N} 2[\mathrm{M}$ $-2 \mathrm{H}]^{2-}$ and methyl esterified NA2 $[\mathrm{M}-2 \mathrm{H}]^{2-}$, at -42 $\mathrm{V}$ for $\mathrm{N} 2\left[\mathrm{M}+2\left(\mathrm{NO}_{3}\right)\right]^{2-}$, and $-58 \mathrm{~V}$ for NA2 [M $2 \mathrm{H}]^{2-}$. This trend indicates that the overall energetics of fragmentation of methyl esterified NA2 $[\mathrm{M}-2 \mathrm{H}]^{2-}$ resemble those of $\mathrm{N} 2[\mathrm{M}-2 \mathrm{H}]^{2-}$. A-type ions formed from cleavage to the antenna GlcNAc residues (termed ${ }^{0,2} \mathrm{~A}_{\mathrm{A}}$, Figure $4 \mathrm{~b}$ ) are abundant for N2 $[\mathrm{M}-2 \mathrm{H}]^{2-}, \mathrm{N} 2$ $\left[\mathrm{M}+2\left(\mathrm{NO}_{3}\right)\right]^{2-}$, and methyl esterified NA2 $[\mathrm{M}-2 \mathrm{H}]^{2-}$ and not observed for NA2 $[\mathrm{M}-2 \mathrm{H}]^{2-}$, indicating that the energetics of the precursor ion and the placement of charge are conducive to their formation. The D-type ion to the branching Man residue (termed core D-ion, 
(a)

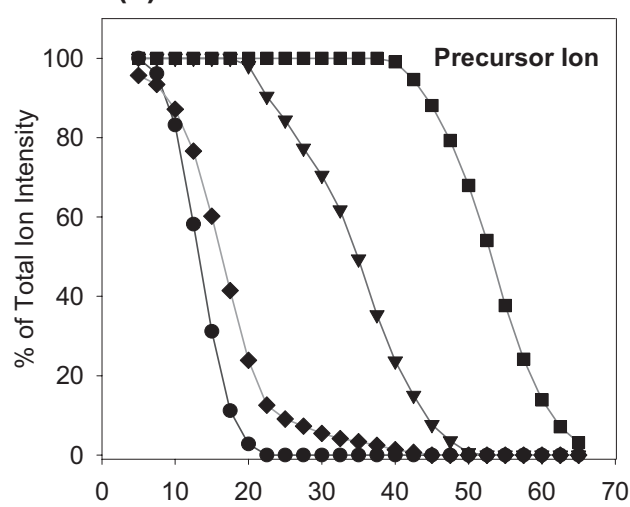

(b)

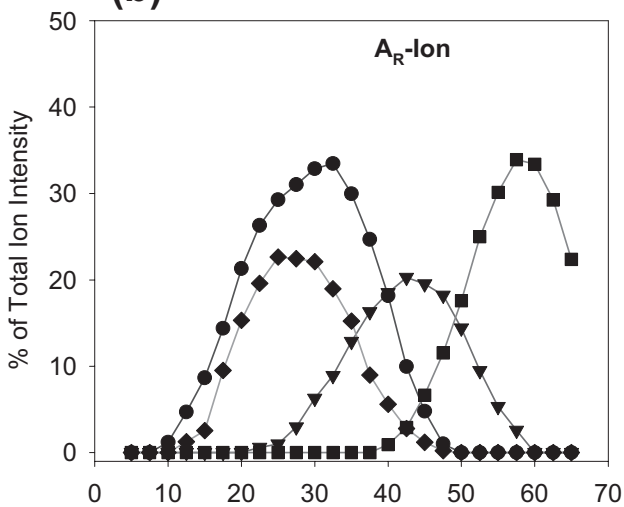

(c)

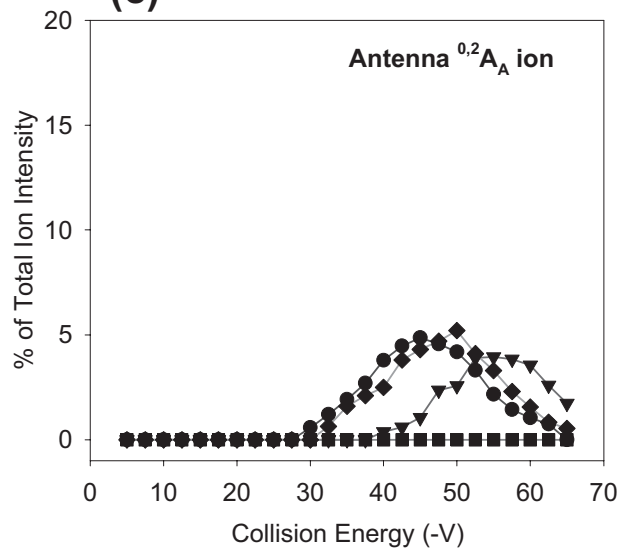

(d)

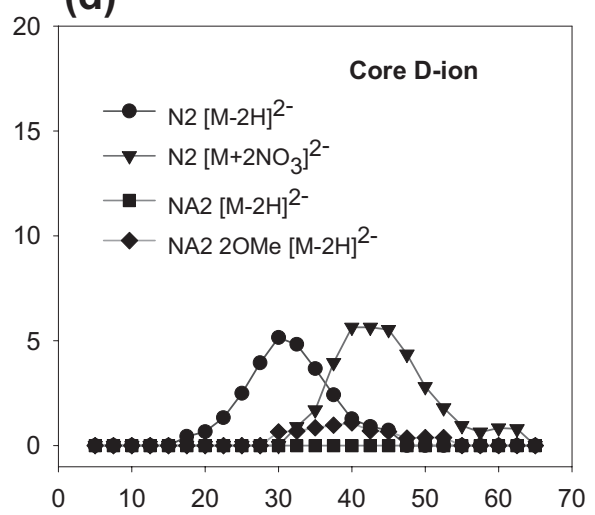

(e)

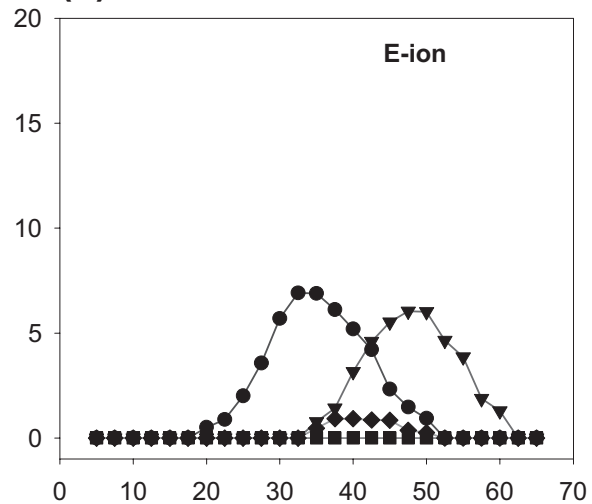

(f)

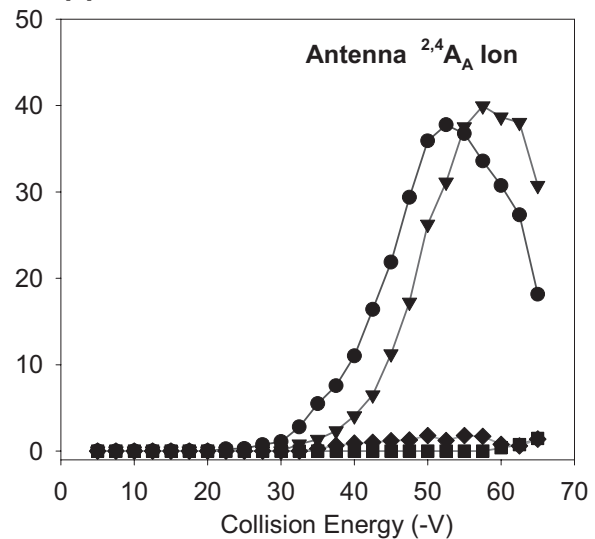

Figure 4. Abundances of precursor and product ions generated from N2 $[\mathrm{M}-2 \mathrm{H}]^{2-}, \mathrm{N} 2[\mathrm{M}+$ 2( $\left.\left(\mathrm{NO}_{3}\right)\right]^{2-}$, NA2 $[\mathrm{M}-2 \mathrm{H}]^{2-}$, and methyl esterified NA2 $[\mathrm{M}-2 \mathrm{H}]^{2-}$ as a function of collision energy. (a) Precursor ions, (b) reducing terminal A-type ions $\left(A_{R}\right),(c)$ antenna ${ }^{0,2} \mathrm{~A}$-type ions $\left({ }^{0,2} \mathrm{~A}_{\mathrm{A}}\right),(\mathrm{d}) \mathrm{D}$-type cleavage to core branching mannose residue, (e) E-type ion, (f) ${ }^{2,4} \mathrm{~A}$-type ion to antenna mannose $\left({ }^{2,4} A_{A}\right)$. Tandem mass spectra were acquired within a mass range of $100-2000 \mathrm{u}$.

Figure $4 \mathrm{~d})$ is abundant for N2 $[\mathrm{M}-2 \mathrm{H}]^{2-}$ and N2 $[\mathrm{M}+$ $\left.2\left(\mathrm{NO}_{3}\right)\right]^{2-}$, less abundant for methyl esterified NA2 [M $-2 \mathrm{H}]^{2-}$ and not detected for NA2 $[\mathrm{M}-2 \mathrm{H}]^{2-}$. The abundances of the E-ion (Figure 4e), and the A-ion to the antenna Man residues (termed ${ }^{2,4} \mathrm{~A}_{\mathrm{A}}$, Figure $4 \mathrm{f}$ ) are low for methyl esterified NA2 $[\mathrm{M}-2 \mathrm{H}]^{2-}$. It is likely facile losses of methanol from A-type cleavage ions to the core GlcNAc residues reduce the abundances of these ions. The fact that the abundances of these ions are low or absent for the NA2 $[\mathrm{M}-2 \mathrm{H}]^{2-}$ ion is consistent with the conclusion that the presence of Neu5Ac strongly influences the fragmentation mechanism. A substantial fraction of the total product ion abundance goes to the formation of the $\mathrm{B}_{1}$ ion, diminishing the abundances of ions that provide information on the 3- and 6-branches. Methyl esterification alters the dissociation energetics to resemble those of N2 [M $2 \mathrm{H}]^{2-}$. 
(a) $L e^{x}$

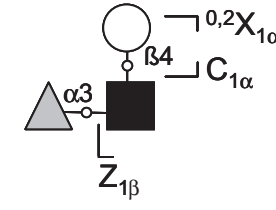

(b) $s L e^{x}$

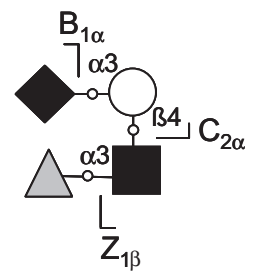

(c)

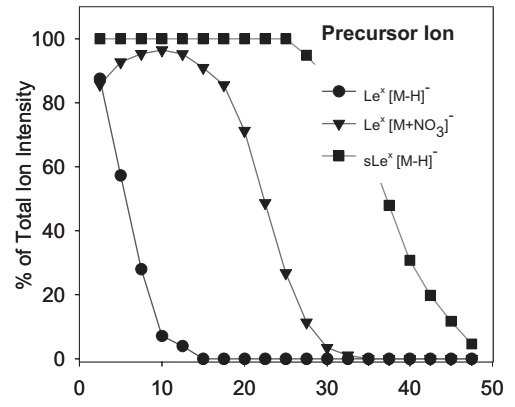

(d)

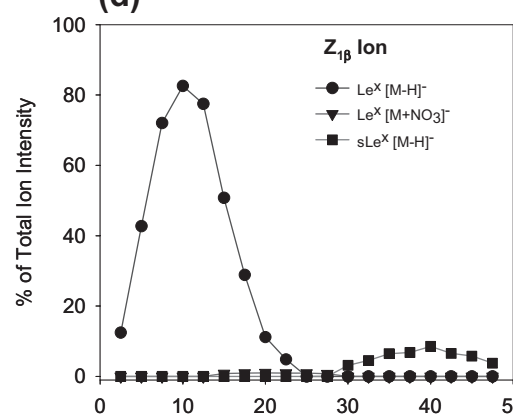

(e)

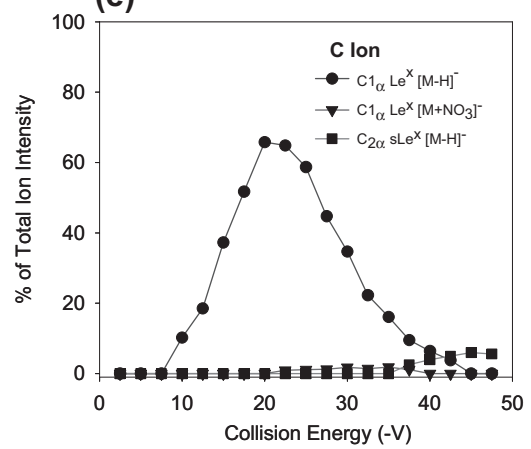

(f) $L e^{a}$

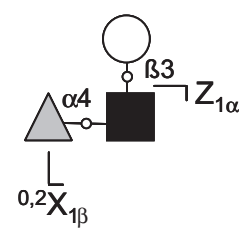

(g) sLe $e^{a}$

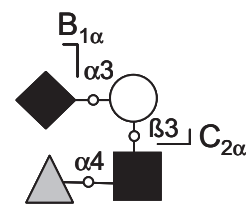

(h)
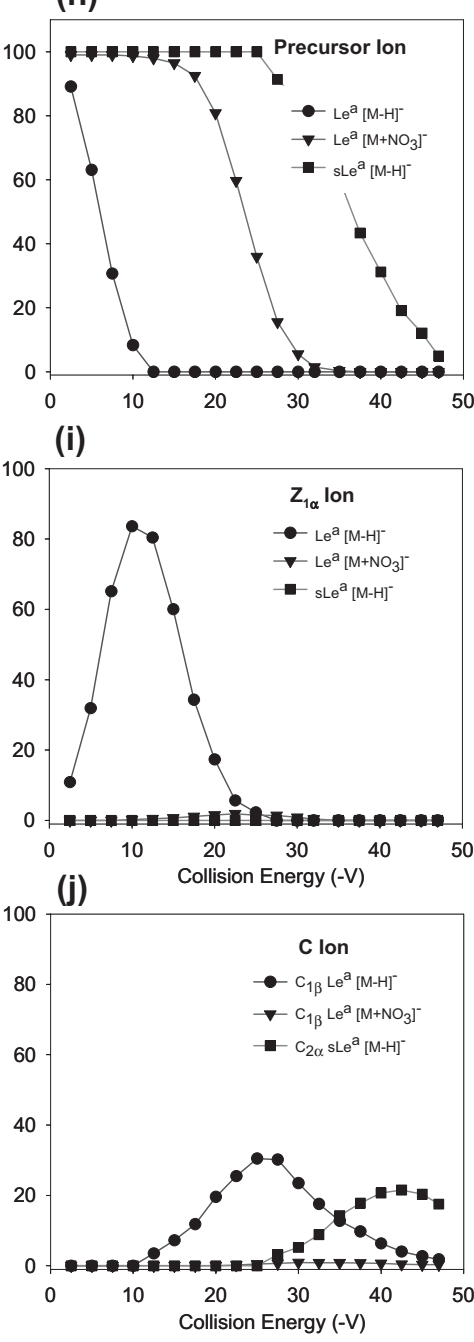

Figure 5. Diagrammatic representation of tandem mass spectra of $\operatorname{Le}^{\mathrm{x}}, \mathrm{sLe}^{\mathrm{x}}(\mathbf{a}),(\mathbf{b})$, and $\operatorname{Le}^{\mathrm{a}}, \mathrm{sLe}^{\mathrm{a}}(\mathbf{f})$, (g). The product ion abundances relative to the precursor ion are as follows: ion, $\mathrm{m} / \mathrm{z}$, relative abundance. (a) $\mathrm{Le}^{\mathrm{x}} \mathrm{CE}-10 \mathrm{~V}: \mathrm{C}_{1 \alpha}, 179.07,111 ; \mathrm{Z}_{1 \beta} /{ }^{2,4} \mathrm{X}_{1 \alpha}, 304.12,15 ; \mathrm{Z}_{1 \beta}, 364.14,921 ;[\mathrm{M}-\mathrm{H}]^{-}$, 528.22, 100; (b) $\mathrm{SLe}^{\mathrm{x}} \mathrm{CE}-37.5 \mathrm{~V}: \mathrm{B}_{1 \alpha^{\prime}}, 290.11,80 ; \mathrm{C}_{2 \alpha^{\prime}}, 470.15,5 ; \mathrm{Z}_{1 \beta}, 655.22,19 ;[\mathrm{M}-\mathrm{H}]^{-}, 819.28,100$; (c)-(e) plots of ion abundances versus collision energy for $\operatorname{Le}^{\mathrm{x}}$ and $\mathrm{sLe}^{\mathrm{x}}$ (c) precursor ion; (d) $Z_{1 \beta}$ ion; (e) C ion; (f) $\mathrm{Le}^{\mathrm{a}} \mathrm{CE}-10 \mathrm{~V}: \mathrm{Z}_{1 \alpha} /^{2,4} \mathrm{X}_{1 \beta}, 288.13,77 ; \mathrm{Z}_{1 \alpha}, 348.15,813 ;[\mathrm{M}-\mathrm{H}]^{-}, 528.21,100 ;(\mathrm{g}) \mathrm{sLe} \mathrm{C}^{\mathrm{a}} \mathrm{CE}$ $-37.5 \mathrm{~V}: \mathrm{B}_{1 \alpha}, 290.11,35 ; \mathrm{C}_{2 \alpha}, 470.17,57 ;[\mathrm{M}-\mathrm{H}]^{-}, 819.26,100 ;(\mathbf{h})-(\mathbf{j})$ plots of ion abundances versus collision energy for $\mathrm{Le}^{\mathrm{a}}$ and $\mathrm{sLe}^{\mathrm{a}}$, (h) precursor ion; (i) $\mathrm{Z}_{1 \alpha}$ ion; (j) $\mathrm{C}$ ion. Tandem mass spectra were acquired within a mass range of 5-2000 u. Symbols are defined in Figure 1. 


\section{Lewis Antigens}

Tandem mass spectra of Lewis antigens are described diagrammatically in Figure 5. The asialo compounds, $\mathrm{Le}^{\mathrm{x}}$ and $\mathrm{Le}^{\mathrm{a}}$ differ in the linkage of the fucose and galactose residues. In Le ${ }^{\mathrm{x}},(\alpha 1-3)$ linked Fuc, and ( $\left.\beta 1-4\right)$ linked $\mathrm{Gal}$ are attached to the central GlcNAc residue. In $\mathrm{Le}^{\mathrm{a}}$, ( $\left.\beta 1-3\right)$ linked Gal, and ( $\left.\alpha 1-4\right)$ linked Fuc are attached to the central GlcNAc residue. For both structures, loss of the 3-linked residue produces an abundant Z-type ion (see Figure $5 \mathrm{a}$ and $\mathrm{f}$ ). For Le $\mathrm{Le}^{\mathrm{x}}$, the most abundant fragment ion is $Z_{1 \beta}$ at $m / z 364.14$ and for Le ${ }^{a}$ the $Z_{1 \alpha}$ ion at $m / z 348.15$ is similarly abundant. An ion is observed at $\mathrm{m} / \mathrm{z} 304.12$ in the tandem mass spectrum of $\mathrm{Le}^{\mathrm{x}}$ that corresponds to the loss of $60 \mathrm{u}$ from the $\mathrm{Z}_{1 \beta}$ ion. According to the nitrogen rule, this ion should contain a nitrogen atom; it appears to derive from fragmentation of the Gal residue, and is consistent with the formation of a $Z_{1 \beta} /{ }^{2,4} X_{1 \alpha}$ ion. An analogous ion, $\mathrm{Z}_{1 \alpha} /{ }^{2,4} \mathrm{X}_{1 \beta}$, is observed in the tandem mass spectrum of $\mathrm{Le}^{\mathrm{a}}$ (Figure 5f) at $\mathrm{m} / \mathrm{z} 288.13$, produced from fragmentation of the Fuc residue. These are examples in which the limited fragmentation pathways available to a disaccharide (i.e., the $Z_{1}$ ion) allow formation of $X$-type ions that require comparatively high collision energies.

The sialylated variants, $\mathrm{sLe}^{\mathrm{x}}$ and $\mathrm{sLe}^{\mathrm{a}}$, shown in Figure $5 \mathrm{~b}$ and $\mathrm{g}$, produce abundant $\mathrm{B}_{1}$ ions containing the Neu5Ac residue. Despite this, the $C$ - and Z-type ions are also relatively abundant. $\mathrm{A}_{1 \beta}$ ion at $m / z 655.22$ is observed for $\mathrm{sLe}^{\mathrm{x}}$, analogous to the $Z_{1 \beta}$ ion observed for Le ${ }^{\mathrm{x}}$. Significantly, sLe ${ }^{\mathrm{a}}$ lacks a $Z_{1 \alpha}$ ion, despite the fact that an analogous ion is observed for Le ${ }^{\mathrm{a}}$. Retention of charge by the Neu5Ac residue gives rise to an abundant $\mathrm{C}_{2 \alpha}$ ion in the case of $\mathrm{sLe}^{\mathrm{a}}$, disfavoring formation of a $Z_{1 \alpha}$ ion. The fact that $C$ - and $Z$-type ions are abundant for the Lewis structures is likely to result from their comparatively small size. For the LST structures, three residues separate the Neu5Ac from the reducing terminus, compared to the intervention of only a single residue in the Lewis structures. Thus, the transfer of charge to a reducing terminal ring hydroxyl group that facilitates C- and Z-ion formation is likely more facile for the Lewis structures.

Dissociation energetics of the Lewis antigens are shown in Figure 5. It became apparent during these studies that the abundances of product ions from cleavage to the glycan structures for nitrated $\mathrm{Le}^{\mathrm{x}}$ and $\mathrm{Le}^{\mathrm{a}}$ were significantly lower than those for the deprotonated precursor ions. Accordingly, the mass range was extended to $5-2000 \mathrm{u}$, to allow inclusion of the $\mathrm{NO}_{3}{ }^{-}$ ion at $\mathrm{m} / \mathrm{z} 62.00$ in plots of percent total ion abundances. Figure $5 c$ demonstrates that $\mathrm{Le}^{\mathrm{x}}[\mathrm{M}-\mathrm{H}]^{-}$requires only $-6 \mathrm{~V}$ to reduce the precursor ion intensity by $50 \%$, significantly less energy than for the $\mathrm{Le}^{\mathrm{x}}\left[\mathrm{M}+\mathrm{NO}_{3}\right]^{-}$ $(-22 \mathrm{~V})$ and $\mathrm{sLe}^{\mathrm{x}}[\mathrm{M}-\mathrm{H}]^{-}(-37 \mathrm{~V})$ ions. Similar trends were observed for variants of $\mathrm{Le}^{\mathrm{a}}$, Figure $5 \mathrm{~h}$, where the $[\mathrm{M}-\mathrm{H}]^{-}$ion required significantly less energy $(-7 \mathrm{~V})$ for $50 \%$ reduction of precursor intensity compared to those for $\mathrm{Le}^{\mathrm{a}}\left[\mathrm{M}+\mathrm{NO}_{3}\right]^{-}(-23 \mathrm{~V})$ and $\mathrm{SLe}^{\mathrm{a}}(--36 \mathrm{~V})$.
The formation of the Z-type ions from cleavage to the 3-linked residue is plotted in Figure $5 d$ for $\operatorname{Le}^{x}$ and Figure 5i for $\mathrm{Le}^{\mathrm{a}}$. This ion is most abundant for [M $\mathrm{H}]^{-}$precursors at approximately $-10 \mathrm{~V}$ collision energy and diminishes at higher energies $(-V)$ due to sub-fragmentation. For nitrated $\mathrm{Le}^{\mathrm{x}}$ and $\mathrm{Le}^{\mathrm{a}}$, the Z-ion is observed at very low percent abundances. Sialyl $\mathrm{Le}^{\mathrm{x}}$ produces a $Z_{1 \beta}$ ion observed at maximum abundance at $-40 \mathrm{~V}$ collision energy. The $Z_{1 \alpha}$ ion is observed at very low abundance for sLe ${ }^{\mathrm{a}}$.

The formation of $\mathrm{C}$ ions for Lewis structures varies greatly among $[\mathrm{M}-\mathrm{H}]^{-},\left[\mathrm{M}+\mathrm{NO}_{3}\right]^{-}$, and the sialylated variant $[\mathrm{M}-\mathrm{H}]^{-}$precursors. The breakdown profile in Figure 5e shows the formation of C-type ions from $\mathrm{Le}^{\mathrm{x}}$-type glycans. Le $\mathrm{x}^{\mathrm{x}}$ forms a $\mathrm{C}_{1 \alpha}$ ion significantly more readily than do the nitrated and sialylated forms. The abundance of this ion is dramatically reduced for the $\left[\mathrm{M}+\mathrm{NO}_{3}\right]^{-}$precursor ion. Sialyl Le ${ }^{\mathrm{x}}$ dissociates to form a $\mathrm{C}_{2 \alpha}$ ion, with abundance still increasing at -47.5 $\mathrm{V}$ collision energy. Deprotonated $\mathrm{Le}^{\mathrm{a}}$ produces a relatively abundant $C_{1 \beta}$ ion from cleavage of the 4-linked Fuc residue, with a maximum abundance at $-25 \mathrm{~V}$ (Figure 5j). An analogous ion from dissociation of the 4-branch is absent in tandem mass spectra of $\mathrm{SLe}^{\mathrm{a}}$; instead, a $C_{2 \alpha}$ ion is observed, with maximum abundance at $-45 \mathrm{~V}$. This ion forms from dissociation of the Galß3GlcNAc bond, as in the $Z_{1 \alpha}$ ion observed for Le $^{a}$ (Figure 5i) albeit with charge retention on the opposite side. Nitrated $\mathrm{Le}^{\mathrm{a}}$ forms a $\mathrm{C}_{1 \beta}$ ion in very low abundance relative to the deprotonated precursor ion form.

Figure 6 illustrates the effect of nitration on glycan product ion profiles in the negative mode. As shown in Figure 6a, $\mathrm{Le}^{\mathrm{a}}\left[\mathrm{M}+\mathrm{NO}_{3}\right]^{-}$forms an abundant $\mathrm{NO}_{3}{ }^{-}$ion at $m / z 62.00$ with product ions resulting from glycan cleavage in very low relative abundances. A similar trend is observed for $\mathrm{N} 2\left[\mathrm{M}+2\left(\mathrm{NO}_{3}\right)\right]^{2-}$, in which $\mathrm{m} / \mathrm{z} 62.00$ is the most abundant product ion (Figure 6b). Both Le ${ }^{\mathrm{a}}$ and $\mathrm{N} 2$ contain a reducing end GlcNAc residue and fragment to produce $\mathrm{NO}_{3}{ }^{-}$as the most abundant product ion. By contrast, LNnT, a glycan with a reducing end Glc residue, forms abundant ions from dissociation of glycan bonds, with the $\mathrm{NO}_{3}{ }^{-}$ion at $\mathrm{m} / \mathrm{z} 62.00$ in lower relative abundance (Figure $6 \mathrm{c}$ ). Thus, the product ion pattern for a second glycan with reducing end Glc, LNDFH I, was tested. A similar trend is observed for the LNDFH I [M + $\left.\mathrm{NO}_{3}\right]^{-}$precursor ion (Figure $6 \mathrm{~d}$ ) in that the abundance of the $\mathrm{NO}_{3}{ }^{-}$ion is only moderate relative to those produced from glycan bond cleavage. The Figure 6 insets plot the abundances of the nitrated precursor ions and $\mathrm{NO}_{3}{ }^{-}$ product ions for the four glycans. Dissociation of $\mathrm{NO}_{3}{ }^{-}$ occurs at significantly lower energies for $\mathrm{Le}^{\mathrm{a}}$ and N2 than for LNnT and LNDFH I. These results are consistent with the conclusion that nitrate dissociates from reducing end GlcNAc residues at significantly lower energies than for reducing end Glc residues. Such low-energy dissociation disfavors the formation of ions from dissociation of glycan bonds. 


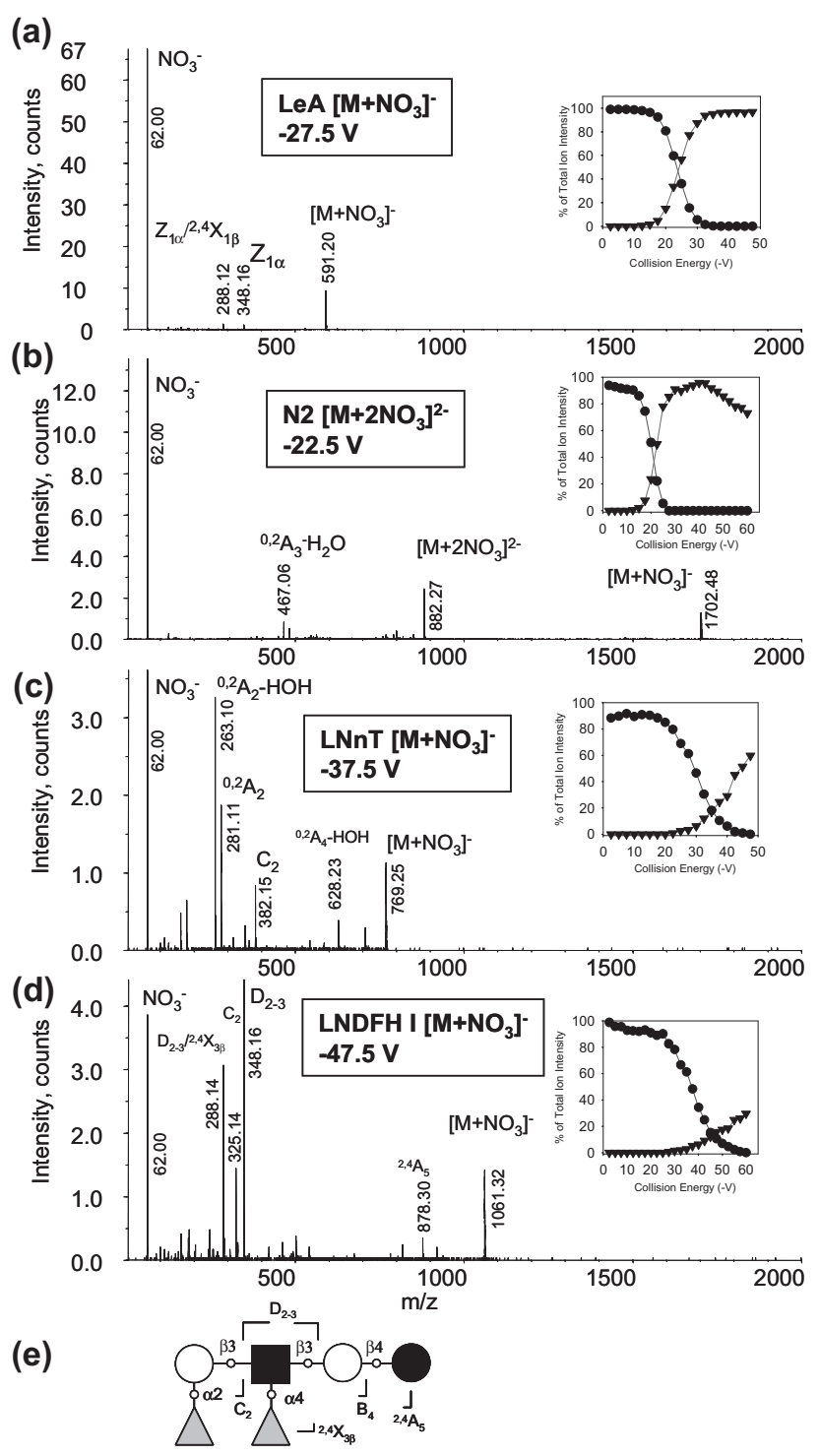

Figure 6. Tandem mass spectra of nitrated glycans (a) $\mathrm{Le}^{\mathrm{a}}[\mathrm{M}+$ $\left.\mathrm{NO}_{3}\right]^{-}$, (b) $\mathrm{N} 2\left[\mathrm{M}+2\left(\mathrm{NO}_{3}\right)\right]^{2-}$, (c) LNnT $\left[\mathrm{M}+\mathrm{NO}_{3}\right]^{-}$and (d) LNDFH I $\left[\mathrm{M}+\mathrm{NO}_{3}\right]^{-}$. The structure and fragmentation diagram of LNDFH I is shown in (e). Structures of the other glycans are shown in other figures. The inset for each spectrum shows breakdown diagrams for the precursor ion (filled circle) and nitrate ion $(\mathrm{m} / \mathrm{z} 62.00$, inverted filled triangle).

\section{Conclusions}

The electrolytic nature of the electrospray process drives the formation of charge on the droplet surfaces that results in the ionization of molecules, even those that lack acidic or basic groups [43, 44]. In the negative mode, hydroxyl anions presumably accumulate on droplet surfaces and extract protons from oligosaccharides, including those lacking acidic groups. The extraction of a proton from a ring hydroxyl group may be viewed, qualitatively, as imparting significantly more energy to the ion than would that from a molecule bearing an acidic group. The present results show that deprotonated ions generated from neutral oligosaccha- rides require significantly less input of energy during the CID process than do those for sialylated variants. Thus, the energetic driving force behind the formation of the deprotonated precursor ions appears to produce optimal results in terms of the abundances of the valuable $\mathrm{A}$ - and $\mathrm{D}$-type product ions.

Deprotonated precursor ions produce abundant $\mathrm{C} / \mathrm{Z}$ (D-type) that differentiate 3- and 6-branches and less abundant A-type cross ring cleavages to antenna HexNAc residues, that differentiate type- 1 and type- 2 structures. However, the presence of Neu5Ac residues dramatically changes the spectral pattern, and the application of these principles is most straightforward for asialo-glycans. Likely an $\mathrm{MS}^{\mathrm{n}}$ strategy for sialylated glycans will improve the abundances of critical product ions that are not observed using a single stage of dissociation. Methyl esterification of sialylated oligosaccharides suffices to produce ion patterns that resemble those of neutral glycans, but with diversion of ion current into pathways involving methanol losses as a mitigating factor.

The generation of useful tandem mass spectra from native glycans in the negative mode relies on the ability to produce fragment ions that require multiple bond cleavages. Formation of the important D-type ions in negative tandem mass spectra of neutral glycans appears to be driven by the input of energy during the ionization process. Creation of an ion with a deprotonated ring hydroxyl group increases its energy to the point that abundant product ions are formed with little further input of energy. For nitrated ions, the dissociation to form $\mathrm{NO}_{3}^{-}$ precursors competes against the cleavage of glycan bonds, and for this reason the use of deprotonated ions is preferred. Analysis of deprotonated ions requires careful control of the electrospray source conditions to prevent in-source fragmentation. Use of nitrated ions will reduce problems associated with excessive ion fragility in the source, but will decrease the abundances of ions formed from dissociation of glycan bonds during CID. Sialylated glycans pose a problem, both because of the increase in energy required for their fragmentation and losses of Neu5Ac in the form of $B_{1}$ ions that diminish the abundances of A-, D-, and E-type ions that provide information on branching structure.

Ultimately, it is useful to acquire automated tandem mass spectra for native glycans eluting from a chromatography column. For such experiments, it will be difficult to find global tandem mass spectrometric settings that are appropriate for asialo and sialylated glycans simultaneously. Therefore, separation of the glycans into neutral and acidic pools $[45,46]$ is recommended. In this way, collision energy settings may be tailored to the fragmentation behavior of asialo and sialylated glycans, using the principles described in the present work. Alternatively, methyl esterification or other sialic acid modifications [47] may be pursued to neutralize the sialic acid groups, rendering their fragmentation behavior equivalent to those of asialo glycans. 


\section{Acknowledgments}

The authors gratefully acknowledge the National Institutes of Health for financial support (grants P41RR10888 to CEC and R01HL74197 to JZ).

\section{References}

1. Domon, B.; Costello, C. E. A systematic nomenclature for carbohydrate fragmentations in FAB-MS/MS spectra of glycoconjugates. Glycoconj. J. 1988, 5, 397-409.

2. Gillece-Castro, B. L.; Burlingame, A. L. Oligosaccharide characterization with high-energy collision-induced dissociation mass spectrometry. Methods Enzymol. 1990, 193, 689-712.

3. Zaia, J. Mass spectrometry of oligosaccharides. Mass Spectrom. Rev. 2004, 23, 161-227.

4. Mechref, Y.; Novotny, M. V.; Krishnan, C. Structural characterization of oligosaccharides using MALDI-TOF/TOF tandem mass spectrometry. Anal. Chem. 2003, 75 , 4895-4903.

5. Lewandrowski, U.; Resemann, A.; Sickmann, A. Laser-induced dissociation/high-energy collision-induced dissociation fragmentation using MALDI-TOF/TOF-MS instrumentation for the analysis of neutral and acidic oligosaccharides. Anal. Chem. 2005, 77, 3274-3283.

6. Huberty, M. C.; Vath, J. E.; Yu, W.; Martin, S. A. Site-specific carbohydrate identification in recombinant proteins using MALD-TOF MS Anal. Chem. 1993, 65, 2791-2800.

7. Juhasz, P.; Biemann, K. Mass spectrometric molecular-weight determination of highly acidic compounds of biological significance via their complexes with basic polypeptides. Proc. Natl. Acad. Sci. U.S.A. 1994, 91, 4333-4337

8. Juhasz, P.; Biemann, K. Utility of noncovalent complexes in the matrixassisted laser desorption ionization mass spectrometry of heparinderived oligosaccharides. Carbohydr. Res. 1995, 270, 131-147.

9. Harvey, D. J.; Naven, T. J. P.; Küster, B.; Bateman, R. H.; Green, M. R.; Critchley, G. Comparison of fragmentation modes for the structural determination of complex oligosaccharides ionized by matrix-assisted laser. Rapid Commun. Mass Spectrom. 1995, 9, 1556-1561.

10. Chai, W.; Piskarev, V.; Lawson, A. M. Negative-ion electrospray mass spectrometry of neutral underivatized oligosaccharides. Anal. Chem. 2001, 73, 631-657.

11. Harvey, D. J. Fragmentation of negative ions from carbohydrates: Part 1. Use of nitrate and other anionic adducts for the production of negative ion electrospray spectra from N-linked carbohydrates. J. Am. Soc. Mass Spectrom. 2005, 16, 622-630.

12. Michalski, J. C.; Peterkatalinic, J.; Egge, H.; Pazparente, J.; Montreuil, J.; Strecker, G. Behavior of the 2-acetamido-2-deoxy- $\alpha$-D-glucopyranosyl residue during sequential hydrazinolysis, N-reacetylation, reduction, and methylation of glycoasparagines. Carbohydr. Res. 1984,134, 177-189.

13. Egge, H.; Peter-Kalalinic, J.; Hanfland, P. Structure analysis of glycosphingolipids using fast atom bombardment (FAB) techniques. Adv. Exp. Med. Biol. 1984, 174, 55-63.

14. Bruntz, R.; Dabrowski, U.; Dabrowski, J.; Ebersold, A.; Peter-Katalinic, J.; Egge, H. Fucose-containing oligosaccharides from human milk from a donor of blood group 0 Le(a) nonsecretor. Biol. Chem. Hoppe-Seyler $1988,369,257-273$.

15. Arita, M.; Iwamori, M.; Higuchi, T.; Nagai, Y. Negative ion fast atom bombardment mass spectrometry of gangliosides and asialo gangliosides: A useful method for the structural elucidation of gangliosides and related neutral glycosphingolipids. J. Biochem. (Tokyo) 1983, 94, 249-256.

16. Isobe, R.; Komori>, T.; Abe, F.; Yamauchi, T. Evaluation of positive and negative ion fast atom bombardment mass spectrometry for structural investigations on cardenolide-type cardiac glycosides. Biomed. Environ. Mass Spectrom. 1986, 13, 585-594.

17. Dell, A.; Ballou, C. E. Fast-atom-bombardment, negative-ion mass spectrometry of the mycobacterial O-methyl-D-glucose polysaccharide and lipopolysaccharides. Carbohydr. Res. 1983, 120, 95-111.

18. Domon, B.; Costello, C. E. Structure elucidation of glycosphingolipids and gangliosides using high-performance tandem mass spectrometry. Biochemistry 1988, 27, 1534-1543.

19. Costello, C. E.; Vath, J. E. Tandem mass spectrometry of glycolipids. Methods Enzymol. 1990, 193, 738-768.

20. Dallinga, J. W.; Heerma, W. Reaction mechanism and fragment ion structure determination of deprotonated small oligosaccharides, studied by negative ion fast atom bombardment (tandem) mass spectrometry. Biol. Mass Spectrom. 1991, 20, 215-231.

21. Li, D. T.; Her, G. R. Linkage analysis of chromophore-labeled disaccharides and linear oligosaccharides by negative ion fast atom bombardment ionization and collisional-induced dissociation with B/E scanning. Anal. Biochem. 1993, 211, 250-257.

22. Carroll, J. A.; Ngoka, L.; Beggs, C. G.; Lebrilla, C. B. Liquid secondary ion mass spectrometry/Fourier transform mass spectrometry of oligosaccharide anions. Anal. Chem. 1993, 65, 1582-1587.
23. Sagi, D.; Peter-Katalinic, J.; Conradt, H. S.; Nimtz, M. Sequencing of triand tetraantennary N-glycans containing sialic acid by negative mode ESI QTOF tandem MS. J. Am. Soc. Mass Spectrom. 2002, 13, 1138-1148.

24. Vakhrushev, S. Y.; Zamfir, A.; Peter-Katalinic, J. 0,2An cross-ring cleavage as a general diagnostic tool for glycan assignment in glycoconjugate mixtures. J. Am. Soc. Mass Spectrom. 2004, 15, 1863-1868.

25. Karlsson, N. G.; Schulz, B. L.; Packer, N. H. Structural determination of neutral O-linked oligosaccharide alditols by negative ion LC-electrospray-MSn. J. Am. Soc. Mass Spectrom. 2004, 15, 572-659.

26. Dell, A. F.A.B. Mass spectrometry of carbohydrates. Adv. Carbohydr. Chem. Biochem. 1987, 45, 19-72.

27. Spengler, B.; Dolce, J. W.; Cotter, R. J. Infrared-laser desorption massspectrometry of oligosaccharides-fragmentation mechanisms and isomer analysis. Anal. Chem. 1990, 62, 1731-1737.

28. Carroll, J.; Willard, D.; Lebrilla, C. Energetics of cross-ring cleavages and their relevance to the linkage determination of oligosaccharides. Anal. Chim. Acta. 1995, 307, 431-447.

29. Saad, O. M.; Leary, J. A. Delineating mechanisms of dissociation for isomeric heparin disaccharides using isotope labeling and ion trap tandem mass spectrometry. J. Am. Soc. Mass Spectrom. 2004, 15, 1274-1286.

30. Pfenninger, A.; Karas, M.; Finke, B.; Stahl, B. Structural analysis of underivatized neutral human milk oligosaccharides in the negative ion mode by nano-electrospray MS(n). Part 1: Methodology. J. Am. Soc. Mass Spectrom., 2002, 13, 1331-1340.

31. Pfenninger, A.; Karas, M.; Finke, B.; Stahl, B. Structural analysis of underivatized neutral human milk oligosaccharides in the negative ion mode by nano-electrospray MS(n).(Part 2: Application to isomeric mixtures. J. Am. Soc. Mass Spectrom. 2002, 13, 1341-1348.

32. Cheng, H. L.; Her, G. R. Determination of linkages of linear and branched oligosaccharides using closed-ring chromophore labeling and negative ion trap mass spectrometry. J. Am. Soc. Mass Spectrom. 2002, 13, 1322-1330.

33. Chai, W.; Piskarev, V.; Lawson, A. M. Branching pattern and sequence analysis of underivatized oligosaccharides by combined MS/MS of singly and doubly charged molecular ions in negative-ion electrospray mass spectrometry. J. Am. Soc. Mass Spectrom. 2002, 13, 670-679.

34. Chai, W.; Piskarev, V. E.; Zhang, Y.; Lawson, A. M.; Kogelberg, H. Structural determination of novel lacto-N-decaose and its monofucosylated analogue from human milk by electrospray tandem mass spectrometry and 1H NMR spectroscopy. Arch. Biochem. Biophys. 2005, 434, 116-127.

35. Kogelberg, H.; Piskarev, V. E.; Zhang, Y.; Lawson, A. M.; Chai, W. Determination by electrospray mass spectrometry and 1H-NMR spectroscopy of primary structures of variously fucosylated neutral oligosaccharides based on the iso-lacto-N-octaose core. Eur. I Biochem. 2004, 271, 1172-1186.

36. Harvey, D. J. Fragmentation of negative ions from carbohydrates. Part 2. fragmentation of high-mannose N-linked glycans. J. Am. Soc. Mass Spectrom. 2005, 16, 631-646.

37. Harvey, D. J. Fragmentation of negative ions from carbohydrates. Part 3. fragmentation of hybrid and complex N-linked glycans. J. Am. Soc. Mass Spectrom. 2005, 16, 647-659.

38. Meisen, I.; Peter-Katalinic, J.; Muthing, J. Discrimination of neolactoseries gangliosides with $\alpha 2-3$ - and $\alpha 2-6$-linked $\mathrm{N}$-acetylneuraminic acid by nanoelectrospray ionization low-energy collision-induced dissociation tandem quadrupole TOF MS. Anal. Chem. 2003, 75, 5719-5725.

39. Wheeler, S. F.; Harvey, D. J. Negative ion mass spectrometry of sialylated carbohydrates: Discrimination of $\mathrm{N}$-acetylneuraminic acid linkages by MALDI-TOF and ESI-TOF mass spectrometry. Anal. Chem. 2000, 72, 5027-5039.

40. Chai, W.; Piskarev, V. E.; Mulloy, B.; Liu, Y.; Evans, P. G.; Osborn, H. M. I.; Lawson, A. M. Analysis of chain and blood group type and branching pattern of sialylated oligosaccharides by negative ion electrospray tandem mass spectrometry. Anal. Chem. 2006, 78, 1581-1592.

41. Yamagaki, T.; Nakanishi, H. A new technique distinguishing $\alpha 2-3$ sialyl linkage from $\alpha 2-6$ linkage in sialyllactoses and sialyl- $N$-acetyllactosamines by post-source decay fragmentation method of MALDI-TOF mass spectrometry. Glycoconj. J. 1999, 16, 385-389.

42. Harvey, D. J. Matrix-assisted laser desorption/ionization mass spectrometry of carbohydrates. Mass Spectrom. Rev. 1999, 18, 349-450.

43. Karas, M.; Bahr, U.; Dulcks, T. Nano-electrospray ionization mass spectrometry: Addressing analytical problems beyond routine. Fresenius J. Anal. Chem. 2000, 366, 669-676.

44. Cech, N. B.; Enke, C. G. Practical implications of some recent studies in electrospray ionization fundamentals. Mass Spectrom. Rev. 2001, 20, 362-387.

45. Karlsson, N. G.; Karlsson, H.; Hansson, G. C. Strategy for the investigation of $O$-linked oligosaccharides from mucins based on the separation into neutral, sialic acid- and sulfate-containing species. Glycoconj. I. 1995, 12, 69-76.

46. Wheeler, S. F.; Harvey, D. J. Extension of the in-gel release method for structural analysis of neutral and sialylated $N$-linked glycans to the analysis of sulfated glycans: Application to the glycans from bovine thyroid-stimulating hormone. Anal. Biochem. 2001, 296, 96-100.

47. Sekiya, S.; Wada, Y.; Tanaka, K. Derivatization for stabilizing sialic acids in MALDI-MS. Anal. Chem. 2005, 77, 4962-4968. 